\title{
Características das Famílias, Estruturação da Produção e Estratégias de Comercialização em um Assentamento de Reforma Agrária ${ }^{1}$
}

\author{
Luciane Cristina De Gaspari² e Carlos Armênio Khatounian ${ }^{3}$
}

\begin{abstract}
Resumo: A estruturação dos estabelecimentos rurais está associada às características das famílias e às suas estratégias de inserção no mercado, em termos de geração de renda e exposição a riscos. Para entender essa associação foram estudados os casos de sete famílias assentadas em Araraquara (SP), região dominada por cana-de-açúcar e citros. Os indicadores foram o valor agregado total, o valor agregado por trabalhador, a estrutura e a dinâmica familiar e a organização do trabalho. Os casos incluíram dois estabelecimentos integrados à agroindústria (cana e frango, leite e frango), três estabelecimentos produtores de hortaliças (venda em atacado, semiatacado e direta ao consumidor), um caso de produção exclusivamente para consumo doméstico e um sem nenhuma produção econômica. As famílias vinculadas à agroindústria obtiveram valores agregados mais elevados, mas precisaram fazer investimentos maiores, o que fragilizou seus sistemas de produção frente a riscos. A crise financeira mundial de 2008 quebrou as agroindústrias integradoras e, com elas, as duas propriedades integradas. Para os produtores de hortaliças, para o mercado local, o valor agregado foi inferior ao do das integradas, como também seus investimentos em infraestrutura. A opção pela via de escoamento das hortaliças foi associada ao tamanho, ao conhecimento tecnológico e do mercado pelas famílias.
\end{abstract}

Palavras-chaves: Agricultura familiar; Viabilidade econômica; Assentamento Monte Alegre; Sistemas produtivos; Integração.

Abstract: The structure of farms is associated with family characteristics and to sale strategy, for a given expectation of income generation and risk exposure. To understand this association, seven cases of settled families were studied in a land reform settlement in

1. Data de submissão: 1 de abril de 2015. Data de aceite: 17 de fevereiro de 2016.

2. Escola Superior de Agricultura "Luiz de Queiroz", Piracicaba, São Paulo, Brasil. E-mail: luciane.degaspari@yahoo.com.br

3. Escola Superior de Agricultura "Luiz de Queiroz", Piracicaba, São Paulo, Brasil E-mail: armenio.esalq@usp.br 
Araraquara-SP, Brazil, a region dominated by sugarcane and citrus plantations. The indicators were total aggregated value, the aggregated value per worker, family structure and dynamics and farm-work organization. The cases comprised two farms integrated with agroindustry (sugarcane and chicken, milk and chicken), three vegetable producers (selling in wholesale, semi-wholesale and farmers' market), a family that produced exclusively for household consumption and a family without economic production. Families associated with agroindustry had the highest aggregated values, but had to make greater investments, which increased risk exposure. The world financial crisis of 2008 broke the agroindustries and both integrated properties. Vegetable producers had lower aggregated values than farms integrated with agroindustry, but their investments needs were accordingly lower. The choice for vegetable sale route was associated with family composition and with technologic and market knowledge present in the family.

Key-words: Family farming; Economic viability; Monte Alegre land reform settlement; Production systems, Integration.

Classificação JEL: Q18.

\section{Introdução}

No estabelecimento agrícola familiar, a família é a chave para o entendimento do processo de tomada de decisões referentes à organização produtiva, formas de escoamento, alocação de trabalho e recursos financeiros (SCHNEIDER, 2003). As decisões são orientadas para a realização do projeto futuro que a família tem para o seu estabelecimento e são pautadas pelas suas necessidades, que variam ao longo do ciclo demográfico familiar (CHAYANOV, 1974; SACCO DOS ANJOS, 2003).

As decisões são interpretadas como estratégias, que buscam a reprodução socioeconômica e cultural do grupo familiar. Em outras palavras, as decisões são as respostas que a dinâmica familiar dá às pressões externas e às suas relações com o contexto tendo em vista à realização do projeto futuro (SCHNEIDER, 2003).

O projeto futuro é o reflexo das estratégias de reprodução e expectativas das famílias em relação ao meio em que vivem e à exploração rural e está atrelado à renda. A família agrícola vê a rentabilidade financeira como um fator determinante à continuidade das atividades (FEIDEN, 2001), que é o resultado da organização produtiva e de suas relações com o meio externo como a via de comercialização.

A comercialização direta ao consumidor final é tida como uma forma de aumentar a rentabilidade financeira e fortalecer a agricultura familiar através da eliminação de agentes de comercialização. No entanto, este artigo revela que a via de comercialização mais eficaz na ótica destas famílias assentadas dependerá de fatores relacionados à estrutura familiar e ao estabelecimento rural. Assim, buscou-se discutir alguns elementos ligados à estrutura familiar e à exploração agrícola, que influenciam a família durante o processo de tomada de decisões estratégicas a optar por vias de comercialização ligadas à agroindústria regional, atacadistas intermediários e direto ao consumidor ou até mesmo a nenhuma ligação com o mercado.

O artigo inicia-se com a fundamentação teórica, que propõe os elementos para análise, passando, então, para a descrição resumida dos estabelecimentos estudados e, posteriormente, à discussão dos resultados financeiros obtidos pelas combinações de atividades produtivas e produtos comercializados em diferentes segmentos do mercado, considerando as estratégias organizacionais dos estabelecimentos, como a infraestrutura e características de cada família.

\section{Fundamentação teórica}

Alexander V. Chayanov tende à perspectiva sociológica weberiana, que busca fundamentar a pesquisa na compreensão do sentido que o ator social atribui a sua própria conduta (SACCO 
DOS ANJOS, 2003). Os estudos de Chayanov procuraram explorar os aspectos organizacionais da exploração camponesa a partir de seus elementos morfológicos, como o ciclo demográfico familiar. A ideia é que haja um balanço subjetivo da família entre trabalho e consumo tendo em vista a manutenção da exploração camponesa (CHAYANOV, 1974). A abordagem passa pela natureza da motivação da atividade econômica familiar (SCNHEIDER, 2003).

A proposta de Chayanov coloca a família camponesa como o principal elemento explicativo do processo de tomada de decisão por parte dos indivíduos no tocante à organização produtiva, alocação da força de trabalho, uso dos equipamentos, investimentos e ligações com o meio externo.

[...] El tamaño y la composición de la família trabajadora, el número de sus miembros capaces de trabajar $y$, además la productividad de la unidad de trabajo $y$ - esto es especialmete importante - el grado de esfuerzo de los trabajadores, el grado de autoexplotación, mediante el cual lós miembros laborantes efectuan cierta cantidad de unidades de trabajo em curso del ano (CHAYANOV, 1974, p. 44).

$\mathrm{O}$ entendimento do funcionamento das explorações agrícolas familiares pressupõe a compreensão do modo pelo qual as famílias solucionam seus problemas cotidianos mantendo uma situação de equilíbrio e reprodução social. As explorações são moldadas por condições externas e de acordo com suas necessidades e tensões internas. Em outras palavras, ao longo de seu ciclo demográfico familiar, o grupo doméstico passa por alterações significativas na relação entre o número de consumidores e trabalhadores, e tal feito reflete em um determinado nível de autoexploração correspondente à necessidade de compensar as alterações demográficas (SACCO DOS ANJOS, 2003).

O nível de alteração depende do juízo abstrato da família, que é o fator decisivo para definir o grau de autoexploração do estabelecimento familiar no que tange ao volume da atividade agrícola, intensidade do trabalho e destino da produção. Tal juízo tem como referência a manutenção do balanço entre trabalho e consumo (SCHNEIDER, 2003). Hoje este balanço não é balizado apenas pela satisfação de necessidades de consumo essenciais mas, sim, pelo desejo de desfrutar de um mercado de bens e serviços expandidos, além de acumular capital.

Ao analisar a família é importante compreender o conceito de estratégia, que funciona como um conjunto de ações conscientes e planejadas pela família para alcançar seus objetivos, que é baseada na relação ótima dos fatores de produção (CHAYANOV, 1974). A estratégia não é derivada apenas de um cálculo aritmético, mas orientada pelas necessidades que variam ao longo do ciclo demográfico familiar (SCNHEIDER, 2003).

Não obstante, segundo Sacco dos Anjos (2003), a teoria de Chayanov reduz os camponeses ao status de "consumidores-produtores", que controlam empresas formalmente autônomas. Ademais, é um modelo estático que não garante condições de expandir os complexos mecanismos de ligações com o contexto econômico, que permeiam as formas familiares de produção em diferentes locais e formações históricas (SACCO DOS ANJOS, 2003).

Por outro lado, a estratégia produtiva rege a rentabilidade econômica do estabelecimento familiar e a combinação dos fatores de produção, conforme critérios estabelecidos pela família (SCHNEIDER, 2003), que são fundados na satisfação de suas necessidades (CHAYANOV, 1974), considerando o contexto sociocultural na qual se insere.

A estratégia de produção é expressa na combinação dos fatores produtivos com os socioeconômicos e demográficos e é observada na organização das principais atividades e na forma de comercialização (ANTUNIASI, 1997). Na ótica da família agrícola, a rentabilidade econômica do estabelecimento, que é resultado da combinação das atividades produtivas e dos fatores de produção, deve manter-se vantajosa ao longo do tempo. Com isto, a combinação das atividades agropecuárias tende a se manter e satisfazer as necessidades familiares. 
Ademais, ao analisar a rentabilidade econômica, faz-se necessário compreender como elementos da estrutura familiar e da exploração agrícola, tais como a disponibilidade de trabalho familiar, a experiência dos agricultores, a infraestrutura do estabelecimento e o manejo produtivo, refletem na organização da produção, na forma de comercialização e na rentabilidade do estabelecimento. Deste modo, o intuito da análise é contribuir com a discussão e reflexão de políticas públicas, que visam à promoção de vias de comercialização para agricultura familiar em bases sustentáveis apontando alguns elementos na estrutura familiar e no estabelecimento, que auxiliam na manutenção da forma da combinação das atividades e da organização produtiva.

Os estabelecimentos agrícolas estudados estão situados no assentamento Monte Alegre, localizado em região marcada por paisagens de cana-de-açúcar em monocultivo. $\mathrm{O}$ assentamento se encontra em condições de acesso favoráveis e próximo a sedes municipais, entre elas Araraquara (São Paulo), principal centro urbano e referência para a comercialização dos produtos de modo direto ou por atravessadores.

Em virtude das características fundiárias regionais, da ocupação do solo e da presença de agroindústrias, a integração à agroindústria é uma opção muito frequente entre os assentados (FERRANTE, 2003). Contudo, outra opção é a produção independente, sobretudo de cultivos alimentares, lembrando que, conforme o Censo Agropecuário de 2006, a agricultura familiar responde por grande parte da produção dos alimentos básicos distribuídos em Araraquara, principalmente em feiras, varejões, atacadistas intermediários, refeições coletivas e supermercados (MACHADO e SILVA, 2004).

Neste quadro, a pesquisa visou analisar as diferentes organizações e combinações das atividades produtivas mais frequentes nos estabelecimentos do assentamento Monte Alegre. Como formas de comparação foram empregados indicadores de rentabilidade econômica das diferentes estratégias familiares. Estes valores foram usados como principais indicadores da viabilidade da atividade, ou seja, da manutenção da forma de organização produtiva e de uso do solo do estabelecimento.

\section{Metodologia}

A pesquisa utilizou o enfoque agroecológico e a abordagem sistêmica, conforme Khatounian (2001). Por meio de elementos do estabelecimento, como a infraestrutura produtiva e a estrutura familiar (o ciclo demográfico, a disponibilidade de trabalho, a experiência de vida e expectativas), procurou-se entender de que forma estes elementos influenciam na estratégia de combinação das atividades produtivas, na dinâmica funcional interna dos estabelecimentos e nas vias de comercialização praticadas pelos assentados.

O palco do estudo foi o assentamento rural Monte Alegre em Araraquara (SP). Monte Alegre tem em torno de 385 famílias e área total de 6.595 hectares, dos quais 5.231 ha são agricultáveis (CAMPOI, 2005).

Os estabelecimentos foram amostrados por meio de estudo de casos. Esta amostragem é utilizada em pesquisa de natureza holística e social empírica, que aborda um fenômeno atual no contexto de vida real. A seleção dos casos foi baseada em critérios preestabelecidos, em que se procurou escolher os mais representativos do assentamento Monte Alegre chegando a sete estabelecimentos rurais. A escolha de casos-tipos (estabelecimentos) teve como critério as combinações das atividades agropecuárias mais representativas e diversificadas dos estabelecimentos e as vias de comercialização ou até não comercialização mais expressivas encontradas neste universo amostral, conforme suas lógicas produtivas distintas. A autora desse artigo morou no assentamento durante quatro anos em que realizou atividades em extensão, o que lhe propiciou conhecimento de primeira mão de todo o universo amostral e lhe permitiu selecionar para o presente estudo casos-tipo representativos desse universo.

Os estabelecimentos selecionados incluem dois casos de integração com agroindústrias, 
cana-de-açúcar e frango (1) e leite e frango (2), três dedicados à produção de hortaliças, um comercializando via atacadista intermediário (3), outro de venda para varejáo (4) em semiatacado, e outro fazendo venda direta (5) em feira livre, o sexto com gado de corte extensivo (6), com pouca comercialização, e o sétimo orientado totalmente para consumo doméstico (7), sem nenhuma comercialização.

Os dados para o estudo foram obtidos por meio de entrevistas e questionário estruturado aplicado aos assentados durante o ano agrícola de 2008. Os dados abrangeram informações sobre as lógicas produtivas e de reprodução social da família: sistemas agropecuários, formas de comercialização, distribuição do trabalho, renda, rentabilidade das atividades agrícolas, dependência externa (ligada ao sistema produtivo e ao mercado) e expectativas futuras.

Para avaliação dos resultados econômicos dos sistemas, foram considerados os seguintes conceitos de valor agregado: unidade de trabalhador equivalente e valor agregado por trabalhador (DUFUMIER, 2010), ajustados aos dados efetivamente disponíveis no estabelecimento. $\mathrm{O}$ valor agregado no estabelecimento foi calculado como a diferença entre a receita bruta e o total de despesas na produção num ano agrícola (2008). O número de trabalhadores-equivalentes foi calculado somando-se as porcentagens de tempo de cada pessoa adulta envolvida efetivamente dedicada à atividade produtiva. Por exemplo: o marido em tempo integral e a esposa em $50 \%$ somam 1,5 trabalhador-equivalente, ou o agricultor em tempo integral mais dois trabalhadores contratados por seis meses somam 2,0 trabalhadores-equivalentes.

Dividindo-se o valor agregado pelo número de trabalhadores-equivalentes obtem-se o valor agregado por trabalhador, que estabelece o teto da remuneração que o sistema de produção é capaz de oferecer aos trabalhadores envolvidos. Esse é um valor particularmente importante, porque serve como referência ao agricultor e sua família quanto à pertinência de se manter naquele sistema de produção.

\section{Características dos estabelecimentos rurais}

Nos estabelecimentos voltados à produção de cana-de-açúcar e frango (1) e de leite e frango (2), a integração segue os padrões usuais nas agroindústrias da região ${ }^{4}$. No caso dos estabelecimentos com cana-de-açúcar e frango (1), a família passou a maior parte da vida em meio urbano e, ao final de sua trajetória como assalariado, o marido se instalou no assentamento com capital para investir na exploração. A família é formada pelo casal com 53 e 48 anos, o filho de 25 e o sogro com 76 anos. O marido e a esposa são parcialmente envolvidos no trabalho agrícola. O filho e o avô têm limitações, de modo que não participam na produção agrícola. A mão de obra é tida como escassa pela família.

O estabelecimento de leite e frango (2) pertence a uma família formada por dois casais com 62 e 70 anos, seu filho de 26 e a nora também de 26 anos. O casal mais novo desempenha a atividade rural com facilidade, já o mais velho tem dificuldade; logo, para a família, a disponibilidade de mão de obra é pequena. Esta família ocupou diferentes posições sociais em meio urbano e rural até comprar as benfeitorias e tomar posse do estabelecimento com direito de uso. A infraestrutura produtiva foi adquirida com o capital acumulado em sua trajetória de vida.

As atividades dos estabelecimentos com cana-de-açúcar e frango (1) e leite e frango (2) são caracte-

4. O contrato com o abatedouro de frangos prevê que o integrado se responsabilize pela construção do aviário, instalação de equipamentos e entrega das aves para a agroindústria integradora, que fornece os insumos necessários para a produção. O pagamento é feito de acordo com indicadores técnicos; portanto, a empresa terceiriza a engorda das aves junto aos integrados. Em mesma medida, o contrato de integração com a usina estabelece uma parceria com a prefeitura municipal, que disponibiliza tratores e implementos agrícolas. A usina fornece os insumos e remunera o trabalho. O agricultor fornece a terra e, na maioria dos casos, a mão de obra. As despesas da usina são amortecidas em $50 \%$ do investimento na safra de 1 o corte, $30 \%$ na de 2 o e $20 \%$ na safra de 3 o corte. No contrato de venda do leite, o agricultor se responsabiliza pela qualidade do produto que é entregue ao laticínio com valor pago por litro preestabelecido. 
rizadas pela alta dependência de insumos externos, grandes perdas de subprodutos das atividades que poderiam tornar-se produtos em outras existentes no lote e altos investimentos em infraestrutura produtiva. Logo após a aplicação do questionário, as indústrias integradoras quebraram devido à crise econômica internacional, deixando dívidas junto aos agricultores, de modo que a produção em ambos os estabelecimentos foi paralisada.

No estabelecimento com produção de hortaliças comercializadas com atacadista intermediário (3), a família é formada por pai e filho com 56 e 18 anos, tendo passado toda a vida pré-assentamento no campo como trabalhadores volantes. A dimensão da área de plantio é definida pela mão de obra disponível e pela exigência em trabalho das culturas. Normalmente são cultivadas poucas espécies em monocultura, sendo a escolha da espécie definida em acordo com o intermediário. A produção está alicerçada e é dependente de insumos industriais, mas não depende de financiamento externo, uma vez que os custos produtivos estão dentro da capacidade financeira da família e há baixo investimento em benfeitorias produtivas. O intermediário revende a produção em varejões de Araraquara.

No caso de venda para varejóes (4), a exploração é dirigida por uma família que sempre cultivou hortaliças no município de Araraquara, de modo que tem experiência acumulada tanto nas técnicas de cultivo, quanto no mercado local. A família é formada pelo casal, com 59 e 39 anos de idade e três filhos de 25, 23 e 20 anos que são pluriativos. $\mathrm{O}$ marido tem capacidade de trabalho parcial devido à saúde debilitada. A área produtiva é limitada pela restrição de mão de obra e há mais demanda pelos produtos do que volume ofertado pelo agricultor. As atividades são planejadas em favor de maior autonomia de insumos externos, o que requer mais trabalho. Há pouco investimento em benfeitorias produtivas e há um automóvel para transportar os produtos para os varejões.

No caso da venda direta (5) em feira livre, no mesmo município de Araraquara, o lote pertence à família de ex-colonos de usinas de cana-de-açúcar da região formada pelo casal com 60 e
48 anos, o filho (21 anos), nora (20) e duas netas com 5 anos, que se instalou no assentamento com capital para investir na produção. A combinação produtiva tem pouca dependência de insumos externos, requer grande quantidade de trabalho e as atividades são amparadas por diversas benfeitorias; entre elas, trator e caminhonete.

Sem atividade agrícola comercial, o lote com gado de corte extensivo (6) é mais um local de moradia do que de produção. O pai da família e o filho passaram a maior parte da vida como boias-frias nas periferias das cidades da região, até se aposentarem por invalidez e serem assentados em Monte Alegre. O gado serve como reserva de valor.

Por fim, no último lote analisado a produção é voltada ao consumo doméstico (7) com venda muito esporádica de excedente. A combinação produtiva é de gado semiextensivo e policultivo. O lote é cultivado por família extensa que é formada por 12 membros de idades que variam entre 3 e 70 anos, mas com pouca disponibilidade de mão de obra familiar devido à dinâmica familiar, pluriatividade de alguns membros ou idade e problemas de saúde de outros membros. A família é formada pelo casal, filhos, genros, noras, netos e agregados. O casal e parte dos filhos passaram a vida como colonos e trabalhadores volantes. As atividades são caracterizadas por fraca dependência em relação ao exterior (insumos e mercado), baixo nível técnico, tradicional e poucas compras, vendas e investimentos. A renda monetária é garantida pelo programa "Bolsa Família" e pela aposentadoria. A lógica exposta pelo patriarca da família é que tudo o que compram como insumo é caro, e tudo o que vendem é muito barato, o que explica sua orientação para o consumo doméstico.

\section{Resultados e discussão}

O eixo da discussão parte do resultado financeiro obtido pela combinação das atividades produtivas do estabelecimento e sua interação com o contexto por meio da via de comercialização, tendo em vista a dinâmica familiar. 


\subsection{Renda agrícola, organização produtiva e comercialização}

Na perspectiva do agricultor ligado ao mercado, é a partir da renda monetária agrícola que ele alcançará suas expectativas futuras e a manutenção da combinação das atividades produtivas do estabelecimento rural. Tendo isso em vista, o agricultor toma as decisões e traça suas estratégias. A construção da renda agrícola vem a partir dos valores das vendas e dos gastos produtivos (Tabela 1).

Tabela 1. Valor bruto das receitas e despesas anuais em cinco lotes no assentamento Monte Alegre, Araraquara, SP, em 2008 (R\$ mil)

\begin{tabular}{lcc}
\hline \multicolumn{1}{c}{ Caso } & $\begin{array}{c}\text { Valor das } \\
\text { vendas }\end{array}$ & $\begin{array}{c}\text { Valor dos } \\
\text { gastos }\end{array}$ \\
\hline Frango e cana, agroindústria (1) & 34,5 & 7,0 \\
Frango e leite, agroindústria (2) & 44,0 & 7,0 \\
Hortaliças, atacadista (3) & 16,0 & 2,3 \\
Hortaliças, semiatacado varejão (4) & 20,1 & 1,8 \\
Hortaliças, venda direta feira (5) & 28,2 & 3,4 \\
\hline
\end{tabular}

Fonte: Dados de campo coletados pelos autores.

O valor bruto das receitas depende da via de comercialização e do volume de produção. Para poder avaliar o potencial de remuneração da mão de obra, optou-se por discutir esses valores em termos de salários mínimos (SM), que correspondia a $\mathrm{R} \$ 415,00$ em 2008. Os estabelecimentos ligados à agroindústria são os de maior receita bruta e líquida, 83,13 SM/ano - cana-de-açúcar e frango (1) e 106,03 S.M. /ano - leite e frango (2), sendo que no último há maior volume de produção, conforme Tabela 1. No estudo de caso paulista realizado por Lopes (2007), os produtores de goiaba integrados recebiam valor bruto de vendas menor do que dos não integrados.

Já dentre os estabelecimentos voltados ao mercado local, o escoamento por feira (5) é o que gera a maior receita (67 S.M./ano). A venda direta possibilita que o agricultor obtenha preços maiores por unidade de produto comercializada (GONÇALVES e CEZARRINI, 2008).

Em estabelecimentos que comercializam com o setor atacadista, o valor bruto das vendas é menor (38 S.M./ano - atacadista intermediário (3) e 48 S.M./ano - varejão (4) Tabela 1). Os estabelecimentos diferem pelo número de agentes na comercialização entre o produtor e o consumidor final. Quanto maior o número de agentes, menor o valor bruto das vendas (SOUZA et al., 1998).

Em relação aos gastos na produção, eles dependem da estrutura produtiva ${ }^{5}$ dos estabelecimentos e dos sistemas de manejo, que possibilitam fluxos ${ }^{6}$ (conectividade) entre as atividades. Os fluxos refletem nos custos de produção, uma vez que os fluxos de saída de uma atividade são utilizados como entradas em outras, evitando a aquisição de insumos (FAZENDA MALUNGA, 2009). Por exemplo, o uso do esterco bovino do próprio estabelecimento em outra atividade, como é realizado na a produção de hortaliças para o varejão (4).

Os estabelecimentos ligados à agroindústria são os que mais têm despesas. No estabelecimento com cana-de-açúcar e frango (1), os gastos de custeio representam $20 \%$ do valor das vendas. Na exploração com leite e frango (2), a proporção vai para $16 \%$ (Tabela 1). Isto se deve ao sistema de manejo convencional adotado pela agroindústria.

Os gastos representaram a mesma ordem de valor, $14 \%$ do valor bruto das vendas no estabelecimento que comercializa com atacadista intermediário (3), e é o maior valor dos custos dentre as explorações ligadas ao mercado local (Tabela 1). O sistema é formado principalmente por 0,7 ha de hortaliças e outras atividades complementares. A dependência externa do sistema em relação a insumos químicos é em razão da restrição de mão de obra, ausência do componente animal e nenhum fluxo entre as atividades.

Na exploração de venda para varejão (4), as despesas representam 9\% do valor das vendas é o sistema de produção que gera o menor valor de despesas e a mais eficiente em termos de retorno do capital dentre os sete casos estudados (Tabela 1). O baixo valor das despesas com

5. A estrutura produtiva é formada pelo número de atividades, interação entre elas e tipos de atividades.

6. Os fluxos são as interações que ocorrem na estrutura produtiva e no estabelecimento rural. 
insumos é resultado da organização produtiva com atividades que se conectam entre si gerando fluxos e ao uso de técnicas agroecológicas, semelhante ao caso da produção de tomates descrita por Luz et al. (2007). No caso deste estudo, o fluxo de esterco do gado para a horta.

Já no estabelecimento de venda direta em feira (5), as despesas representam $12 \%$ da receita bruta (Tabela 1), principalmente com mão de obra contratada. Dentre os casos estudados, esse é o de maior demanda por trabalho. Porém, mais importante do que a renda bruta ou a líquida, é a renda gerada por trabalhador envolvido no sistema de produção, porque essa renda por trabalhador define a capacidade de remuneração do sistema (Tabela 2).

A grosso modo, o valor agregado segue a mesma tendência dos valores brutos das vendas e dos gastos (Tabela 2). Os estabelecimentos voltados à agroindústria (1) e (2) apresentaram os maiores valores agregados. Contudo, o caso com produção de hortaliças em venda direta (5) apresentou valor agregado da mesma ordem de grandeza que o caso de integração com frango e cana (1) (Tabela 2), apesar de o investimento ser muitíssimo mais elevado na integração. Neste estudo, as despesas se referem apenas ao custeio, não sendo incluída a depreciação de benfeitorias. Se a depreciação fosse quantificada, é muito provável que o caso hortaliças em venda direta (5) apresentasse maior valor agregado que o da integração com frango e cana (1).

Em termos de capacidade de remuneração da mão de obra, o caso cana-de-açúcar e frango (1) apresentou o melhor desempenho, gerando 38,98 salários mínimos por trabalhador por ano, 3,25 salários por mês. Os casos com hortaliças geraram de 1,5 a 1,8 salário mínimo por trabalhador, por mês. Por sua vez, o caso de frango e leite integrados gerou cerca de 2,25 salários mínimos por trabalhador, por mês, o que é relativamente pouco, considerando-se o vultoso investimento comparado ao da produção de hortaliças.

Considerando-se os casos que trabalham com hortaliças, o potencial de remuneração do trabalho dos sistemas de venda em atacado ou semiatacado foram semelhantes (Tabela 2), a despeito de a lógica agronômica ser sensivelmente diferente, No caso do atacado, trata-se de um sistema monocultor baseado em insumos industriais e produtos tóxicos, enquanto no de semiatacado (varejões) o sistema é baseado na produção diversificada de hortaliças integrada com pequeno plantel bovino mantido especialmente para a produção de esterco e com raríssimo uso de agrotóxicos. Isso torna o sistema que vende em semiatacado mais robusto frente a oscilações no mercado e mais salubre. Nessa perspectiva, emerge a questão de porque os produtores do caso de atacado não se convertem a um modo de produção mais salubre e integrado. As maiores dificuldades para essa conversão parecem estar na menor disponibilidade de mão de obra - família menor - e de não ter veículo próprio para o transporte da produção.

Como em outros casos estudados na literatura, no caso de venda em semiatacado (varejão), a organização do lote e seu manejo efetivamente tornam a produção menos dependente de insumos externos, mas requerem mais trabalho (DULLEY et al., 2003; FAZENDA MALUNGA, 2009).

Tabela 2. Valor agregado, número de trabalhadores-equivalentes e valor agregado por trabalhador em cinco lotes no Assentamento Monte Alegre, Araraquara, SP, 2008. Valores expressos em salários mínimos

\begin{tabular}{lccc}
\hline \multicolumn{1}{c}{ Caso } & Valor Agregado & Trabalhador- equivalente & Valor agregado / Trabalhador \\
\hline Frango e cana, agroindústria (1) & 66,26 & 1,7 & 38,98 \\
Frango e leite, agroindústria (2) & 89,15 & 3,3 & 27,02 \\
Hortaliças, atacadista (3) & 33,01 & 1,5 & 22,00 \\
Hortaliças, semiatacado varejão (4) & 44,10 & 2,2 & 20,04 \\
Hortaliças, venda direta feira (5) & 59,76 & 3,2 & 18,68 \\
\hline
\end{tabular}

Fonte: Dados de campo coletados pelos autores. 
Em suma, os estabelecimentos ligados à agroindústria (1) e (2) geraram a maior receita bruta, maior valor agregado (depreciação não considerada) e o maior potencial de remuneração do trabalho; porém, são os que mais gastam em insumos químicos criando dependência externa e maiores riscos de colapso. O preço dos insumos depende da taxa cambial, do mercado externo e de empresas multinacionais, fatores esses fora do controle dos agricultores. Efetivamente, no ano seguinte ao da realização dessa pesquisa, a crise econômica internacional levou à bancarrota as indústrias integradoras de ambos os casos, e ao colapso econômico de seus sistemas de produção.

Quanto às explorações voltadas ao mercado local (3), (4) e (5) seus indicadores econômicos foram algo inferiores aos das integrações, e elas diferiram entre si quanto ao canal de comercialização, infraestrutura do estabelecimento, manejo e quantidade de trabalho requerido.

Tendo em vista a rentabilidade das atividades produtivas, a discussão sobre a composição da renda total e seu reflexo na escolha das estratégias produtivas está na próxima seção.

\subsection{Composição da renda familiar e seu reflexo na organização produtiva}

Dos sete estabelecimentos estudados, nos de cana-de-açúcar e frango (1) e hortaliças para varejão (3) a renda familiar é formada pela renda agrícola e pela aposentadoria. Nos casos do gado extensivo (6) e consumo doméstico (7), não há geração de renda no lote, sendo a renda oriunda de aposentadoria ou de programas federais de distribuição de renda ("Bolsa Família").

No estabelecimento com cana-de-açúcar $e$ frango (1) ligado à agroindústria, a renda da aposentadoria tem sido investida nas atividades agrícolas, o que tem permitido ao longo do tempo um investimento monetário de maior vulto no arranjo produtivo, e também tem reduzido os efeitos adversos sobre a família por conta das oscilações dos preços agrícolas.

Já o agricultor do gado extensivo (6) foi aposentado por invalidez ainda antes de a família se instalar no assentamento. É a renda da aposentadoria que garante a sobrevivência da família e lhes permite não desenvolver atividades comerciais no lote.

No estabelecimento do consumo doméstico (7), os ingressos provêm da aposentadoria e do programa Bolsa Família, mas não são suficientes para a numerosa família de 12 membros. Esse fato, somado à percepção negativa quanto aos preços recebidos pelos agricultores pelos produtos agrícolas, são declarados pelo chefe da família como a razão de sua opção pela ênfase na produção para consumo doméstico.

Nos três outros casos, dois que produzem hortaliças e um leite e frango, a renda provém quase que exclusivamente das atividades agrícolas conduzidas no lote.

Examinando-se esse conjunto de situações, fica evidente que a existência e o valor da renda externa ao lote são um importante fator na definição de quais atividades agrícolas são conduzidas e do seu modo de inserção na economia regional, como observado por Conterato et al. (2007). Outro fator muito relevante nessa definição é a força de trabalho, que será tratado a seguir.

\subsection{O trabalho e as estratégias de organização produtiva}

As estratégias de organização do trabalho nos estabelecimentos agrícolas são guiadas pelo tamanho, composição e ciclo demográfico das famílias, bem como pela racionalidade de acumulação, conforme foi discutido na fundamentação teórica deste artigo.

Tais fatores também estão relacionados com a busca crescente dos jovens do assentamento Monte Alegre por melhor qualidade de vida e maior renda, por meio do trabalho fora dos lotes. Majoritariamente, ficam no assentamento os homens mais velhos com problemas de saúde, pouco escolarizados e normalmente com baixa qualificação profissional para atividades urbanas. Tudo isso resulta em forte restrição quantitativa e qualitativa de mão de obra familiar nos lotes, comprometendo seu potencial de geração 
de renda. Este fenômeno é generalizado no meio rural brasileiro, conforme estudos do projeto Rururbano ${ }^{7}$.

Quanto à organização do trabalho, nota-se que as estratégias familiares são pautadas pelas características e expectativas da família e sua relação com o contexto geral, como observado por Schneider (2003). Assim sendo, discute-se a seguir de que forma as estratégias de uso do trabalho construídas pela dinâmica familiar resultam no valor agregado dos produtos comercializados durante o ano.

A família com a exploração ligada à agroindústria com cana-de-açúcar e frango (1) buscou atividades com menor frequência de picos de trabalho (bimestral). O estabelecimento gera o segundo valor agregado mais alto $(66,26 \mathrm{SM} / \mathrm{ano})$ e requer 484 jornadas de trabalho com 8 horas, contratando $4,5 \%$ da mão de obra total. As estratégias adotadas pela família visam à redução de mão de obra devido à baixa disponibilidade de trabalho familiar (1,7 trabalhador-equivalente) e a falta de experiência com serviços rurais. O estabelecimento ligado à agroindústria com frango $e$ leite (2) tem o maior valor agregado (89,15 S.M./ ano) e também é o mais exigente em trabalho ( 960 jornadas de trabalho anuais). Apesar de a disponibilidade de mão de obra familiar ser a mais alta dentre os casos, 3,3 trabalhadores-equivalentes, isso não é o suficiente, de modo que 7,5\% da mão de obra total utilizada no sistema é contratada.

Nos sistemas de produção voltados ao mercado local (3), (4) e (5), a frequência de picos de trabalho é semanal, e em todos os estabelecimentos há baixa disponibilidade de mão de obra familiar, segundo os agricultores. Dentre os estabelecimentos voltados ao mercado local, o que pratica a venda direta ao consumidor (5) é o que mais faz uso do trabalho (912 jornadas de trabalho anuais) e também é o segundo que mais dispõe de mão de obra familiar (3,08 trabalhadores-equivalentes), permitindo ao agricultor optar por uma atividade que requer mais trabalho e frequência diária. $\mathrm{O}$

7. Ver: Unicamp, Instituto de Economia Agrícola, <www. eco.unicamp.br>: entrar em economia agrícola; projetos de pesquisa: Projeto Rurbano. escoamento via feiras exige diversificação da produção, preparação de cada unidade e maior tempo gasto na venda em si, atrás da barraca. Os picos de serviços são nos dias que antecedem a feira e é quando se contrata a mão de obra de dois trabalhadores (10,5\% do total anual), sendo a exploração que mais emprega.

Nos fornecedores do setor atacadista, os sistemas de produção são dimensionados para a mão de obra disponível, de modo que não há contratação temporária; afinal, a capacidade de remuneração do sistema não gera valor monetário suficiente para a contratação de trabalhadores externos. No atacadista intermediário (3), a mão de obra familiar é usada em 432 jornadas de trabalho anuais e tem 1,5 trabalhador-equivalentes disponível no estabelecimento. A exploração que atende ao varejão (4) requer 624 jornadas de trabalho e tem disponível 2,16 trabalhadores-equivalente; deste modo, pode praticar um manejo produtivo que requer mais trabalho que o estabelecimento (3).

A baixa disponibilidade de mão de obra $(1,5$ trabalhador-equivalente) e a pequena capacidade em desempenhar o trabalho que requer 432 jornadas de trabalho anual é um dos fatores que explica a lógica produtiva do lote focado no consumo doméstico (7).

De modo geral, a distribuição do trabalho e a inserção produtiva e laboral de cada membro são definidas na dinâmica interna das famílias e nas relações com o meio em que elas estão inseridas (SCHNEIDER, 2003) e são decisivas nas estratégias adotadas. Para os agricultores de Monte Alegre, a capacidade em desempenhar o serviço é o fator determinante na distribuição do trabalho, que está relacionada com a idade e com as condições de saúde.

Em relação à divisão em função do gênero do trabalho, o trabalho das mulheres estava presente tanto nos espaços de produção como nos domésticos (FERRANTE e DUVAL, 2012). Quanto à valorização do trabalho, sua importância reflete a posição que homens e mulheres ocupam na hierarquia familiar e não conforme a natureza do trabalho. 
No que se refere à sazonalidade do trabalho, depende do tipo das atividades, das operações que elas requerem e de sua distribuição no tempo, como as épocas de plantio, aplicação de tratos culturais, e da fase de desenvolvimento do cultivo ou criação. A disponibilidade de mão de obra familiar para fazer frente às exigências dessa sazonalidade é um dos fatores na escolha do tipo de atividade.

Em resumo, a escolha das atividades produtivas depende da quantidade e da qualidade do trabalho que elas requerem, de sua distribuição ao longo do tempo e da competitividade frente a empregos alternativos. Por sua vez, a capacidade de remuneração da atividade define o potencial de contratação de mão de obra externa quando a familiar for limitante. Em termos de geração de postos de trabalho extrafamiliares, os estabelecimentos que mais empregaram foram os dois integrados com a agroindústria (1) e (2) e o de hortaliças em venda direta (5), que apresentaram os maiores valores agregados.

Em todos os casos observou-se que há déficit de mão de obra familiar, que se deve principalmente ao envelhecimento da população e ao êxodo rural, fenômeno também observado por Borges et al. (2004) em pesquisa no Monte Alegre, e em estudos de Abramovay (1998), Kageyama (1997), Graziano da Silva e Del Grossi (2002) no Brasil rural.

De modo geral, considerando-se o conjunto dos casos, a capacidade que o agricultor tem de realizar trabalho, influenciada pela experiência de vida, pela renda e cultura da família, pesou na escolha das lógicas de distribuição do trabalho. A disponibilidade de mão de obra familiar e a capacidade de realização do trabalho agrícola foram pontos fundamentais na escolha da combinação das atividades produtivas. Em todos os estabelecimentos com atividades comerciais o resultado financeiro foi melhor naqueles casos em que houve maior disponibilidade de mão de obra familiar, favorecendo a manutenção do estabelecimento rural, de modo semelhante ao caso dos feirantes de Passo Fundo (RS), estudados por Rocha et al. (2010).
Devido à tendência no aumento do déficit de mão de obra, o futuro das explorações agrícolas torna-se incerto (WANDERLEY, 2009), principalmente nos estabelecimentos em que o trabalho tem maior peso na combinação dos fatores de produção. As condições da mão de obra em Monte Alegre refletem a realidade rural brasileira; todavia, em processo mais adiantado. A partir da compreensão da dinâmica de trabalho nos estabelecimentos, discute-se, a seguir, de que forma a experiência de trabalho do chefe da família influencia na escolha da organização produtiva.

\subsection{A experiência dos chefes das famílias na escolha da organização produtiva}

Os técnicos da agroindústria orientaram todos os procedimentos no manejo do sistema para o chefe da família produtora de cana-de-açúcar e frango (1), que não tinha experiência profissional rural. Nesse caso, em larga medida, a lógica do trabalho urbano se manteve na estratégia do assentado, como observado por Martins (2003).

O chefe da família do estabelecimento com leite e frango (2) explica a vantagem que vê em ser integrado com a agroindústria, pois "gostava de ser colono, não precisava me preocupar em vender", além do que "o que eu mais gosto é de boi". O contrato de produção e venda preestabelecido com a agroindústria garante antecipadamente a venda, despreocupando-o. Este mesmo sentimento foi notado no estudo de Innocentini (2009) e é um forte atrativo para a integração para muitos agricultores.

No estabelecimento que vende ao atacadista intermediário (3), o agricultor passou a vida cuidando de lavouras e quando chegou ao assentamento teve dificuldades para produzir - "o clima e a terra eram diferentes". As instruções quanto ao que, quando e como plantar foram sendo dadas pelo atacadista, que garantia também a compra e o transporte da produção.

Já na exploração com hortaliças para varejóes (4), o chefe da família é filho de produtores de hortifrutigranjeiros em Araraquara e trabalhou 
nessa atividade e nessa mesma cidade por toda a vida. Assim, a organização da propriedade, as principais culturas, sua condução e comercialização se alicerçaram essencialmente no seu próprio conhecimento da produção e do mercado local.

O agricultor, chefe da família que produz hortaliças para venda direta em feira (5) explica sua opção pela convergência de dois fatores. Por um lado, é muito consciente do risco de insucesso com as monoculturas, especialmente do risco de mercado. Por outro lado, tinha experiência com várias espécies de hortaliças, tanto no acervo das olerícolas de inverno (couves, alface, cenoura etc), como em espécies do verão tropical, da cultura cabocla (abóboras, caxi, mandioca, feijão de corda etc.). A venda direta veio através da inserção em política municipal de abastecimento ${ }^{8}$.

Em seu conjunto, a análise desses casos revela que a trajetória de vida dos assentados e sua experiência anterior ao assentamento foi um fator importante na escolha das atividades comerciais, tanto no caso de o agricultor ter experiência agrícola, quanto no caso de não ter. Em outras palavras, como constatou Alentejano (1997) no estado do Rio de Janeiro, a experiência anterior (ou a ausência dela) é um fator muito relevante na definição da ocupação econômica do lote, mas não é necessariamente condicionante nem limitante. Tendo em vista a dinâmica de trabalho dos estabelecimentos, serão discutidos os investimentos em infraestrutura produtiva construídos nos lotes.

\subsection{Investimentos em infraestrutura nos estabelecimentos rurais}

De sete casos estudados, os dois estabelecimentos com benfeitorias produtivas de valores mais altos são os das famílias que já se instalaram no assentamento mais capitalizadas, a saber, as duas integradas à indústria.

Os custos das benfeitorias produtivas dos estabelecimentos ligados à agroindústria (1) e (2) obrigaram os agricultores a recorrer a emprésti-

8. Lei n. 6.570, de 23 de maio de 2007. Trata das atividades do Programa de Comercialização Direta da Produção da Agricultura Familiar "Direto do Campo". mos, tanto no caso do leite quanto dos frangos. Essas agroindústrias exigem infraestrutura produtiva em bom estado de conservação como condição para a integração, sendo que os custos dessa infraestrutura ficam a cargo do agricultor. Por essas razões, esses estabelecimentos ficam fragilizados e dependentes frente ao setor financeiro, com risco de insucesso no caso de oscilações no mercado (FIGUEIREDO et al., 2006). Assim, o elevado valor agregado (Tabela 2), é um forte atrativo para a entrada na integração, mas não revela o risco associado ao endividamento.

Nos estabelecimentos voltados ao mercado local, os investimentos em infraestrutura produtiva são sensivelmente menores. Como exemplo, os investimentos realizados pelo agricultor que comercializa na feira (5), que aproveitou as condições favoráveis de financiamento da década de 1980 para adquirir um trator e implementos e hoje compra equipamentos com recursos próprios. $\mathrm{O}$ produtor que vende para varejóes (4) possui um automóvel para o transporte dos produtos, o que aumenta a fração do valor final do produto de que ele consegue se apropriar (SOUZA et al., 1998).

A visão conjunta dos casos estudados permite algumas conclusões. Os agricultores que se instalaram no assentamento mais capitalizados puderam investir mais em infraestrutura produtiva, na expectativa de maiores rendimentos. Todavia, a obtenção e manutenção da infraestrutura via crédito agrícola pode causar dependência e riscos. Nos estabelecimentos que se orientaram para o mercado local (3), (4) e (5), produzindo hortaliças, a necessidade de investimentos em infraestruturas produtivas foi sensivelmente menor, e menores seus riscos financeiros, embora com maior exigência em termos de trabalho para manter a produção em funcionamento.

\subsection{Os riscos das organizações produtivas}

Os riscos de desagregação dos sistemas produtivos estão associados à dependência externa (LAMARCHE, 1998), e se relacionam com a habilidade que o estabelecimento rural tem de adaptar-se a imprevistos. Neste estudo, os riscos podem 
ser compreendidos em diferentes aspectos: insumos externos, crédito e mercado. Os riscos se relacionam sob duas óticas; uma é originada no processo de produção e a outra, na economia de mercado.

As dependências externas associadas à produção, tais como insumos, capital e financiamento são maiores nos sistemas de manejo adotado pelas agroindústrias (1) e (2). Por força da simplificação de procedimentos tecnológicos, seu padrão de produção não considera as condições particulares de cada propriedade, não permitindo a instalação de um arranjo produtivo que maximize os recursos locais e torne o sistema mais independente de insumos externos (ROCHA, 2010). Além disto, é preciso financiamento para adquirir os equipamentos, o que leva à subordinação ao mercado de crédito e ao aumento dos riscos de desagregação da organização produtiva frente a oscilações no mercado.

Em nenhum dos estabelecimentos voltados ao mercado local tem havido uso de financiamento para custeio das atividades; de modo que há menos risco e mais autonomia. No caso da exploração que atende ao atacadista intermediário (3), apesar da dependência física de insumos químicos, os custos totais são relativamente baixos devido à reduzida dimensão da área de lavouras, de modo que o agricultor não tem recorrido a crédito de custeio.

No estabelecimento com venda para varejão (4), as atividades têm fluxos internos conectados (o principal insumo para as hortaliças é esterco bovino produzido na mesma propriedade), havendo apenas pequenas entradas na forma de sementes e ferramentas. Essa conformação integrada do sistema de produção resulta em maior autonomia produtiva.

A exploração com venda direta (5) tem principalmente entradas de esterco e mão de obra, ambos obtidos localmente; assim, há uma dependência de fatores externos à propriedade, mas não externos à comunidade. Nessa situação, sua fragilidade frente a fatores externos é sensivelmente menor do que a fragilidade dos sistemas integrados à agroindústria, para os quais as possibilidades de crises são maiores.
Efetivamente, todos os sete estabelecimentos estudados passaram pela crise mundial de capitais que emergiu em 2008, mas apenas os estabelecimentos integrados à agroindústria (1) e (2) paralisaram suas atividades e entraram em colapso, forçando os agricultores a buscarem outras estratégias. Entrementes, as explorações que atendem ao mercado local (3), (4) e (5) de alimentos não foram afetadas.

Em suma, o grau de dependência e os riscos externos relacionados ao processo de produção e ao mercado, sobre os quais o agricultor não tem controle, são menores nos estabelecimentos voltados ao mercado local (3), (4) e (5) e aumentam nos que estão vinculados ao mercado global por via da integração com as agroindústrias (1) e (2).

\subsection{As expectativas futuras das famílias em relação às organizações produtivas}

A manutenção e perpetuação dos estabelecimentos dependem das estratégias de reprodução social e do patrimônio rural. O fim último dessa manutenção, na perspectiva dos agricultores, é a realização do projeto de futuro idealizado pelas famílias. Nas entrevistas, todos se identificaram como produtores rurais, o que os leva a terem lógicas de reprodução que buscam manter estratégias de manutenção do seu patrimônio agrícola (CHALITA e PANZUTTI, 2006).

A Tabela 3 mostra as estratégias de reprodução e manutenção do patrimônio agrícola caso os agricultores contassem com recursos no valor de $1 / 4$ do estabelecimento para investir nas atividades agropecuárias, e quais são os fatores que limitam a manutenção do patrimônio rural e o crescimento produtivo, na opinião dos agricultores chefes das famílias.

Em estabelecimentos voltados ao mercado local (3), (4) e (5), cuja produção exige pesada carga de trabalho manual, os agricultores veem como maior necessidade a aquisição de um trator (Tabela 3), com vistas ao aliviar o esforço físico e aumentar o rendimento do seu trabalho. Outra estratégia é a diversificação de atividades para aumentar as alternativas econômicas (Tabela 3). 
Tabela 3. Investimentos produtivos necessários, na visão do agricultor, com vistas a manter o patrimônio agrícola e a permanência dos estabelecimentos e fatores limitantes a sua continuidade

\begin{tabular}{lll}
\hline \multicolumn{1}{c}{ Segmento de mercado } & \multicolumn{1}{c}{ Investiria em } & \multicolumn{1}{c}{ Fatores limitantes } \\
\hline Frango e cana, agroindústria (1) & Diversificação de atividades produtivas & Baixa fertilidade do solo \\
Frango e leite, agroindústria (2) & Equipamento p/ atividades já existentes & Espaço produtivo \\
Hortaliças, atacadista (3) & Trator / Diversificação de atividades produtivas & Baixa fertilidade do solo, mão de obra \\
Hortaliças, semiatacado (4) & Trator / Poço & Água e mão de obra \\
Hortaliças, venda direta (5) & Trator & Baixa fertilidade do solo \\
Gado extensivo, sem comercialização (6) & Trator/ Diversificação de atividades produtivas & Capital de investimento \\
Autoconsumo (7) & Diversificação & Sabedoria \\
\hline
\end{tabular}

Fonte: Dados de campo coletados pelos autores.

A limitação produtiva relacionada à baixa fertilidade natural do solo de Monte Alegre e, segundo Medeiros et al. (2004), comum a outros assentamentos, pode ser parcial ou totalmente contornada. Para contornar esse problema, são necessários mais insumos materiais e conhecimento, e uma reorganização dos sistemas de produção de modo a gerar e circular fertilidade internamente. Mas tais insumos materiais e conhecimento não são dominados hoje pelos agricultores. Uma estratégia alternativa, muito desejável para os agricultores, mas que não apareceu nas respostas, é arrendar área para as usinas de cana-de-açúcar, mas essa alternativa está limitada pelas regras de uso dos assentamentos rurais ${ }^{9}$, que limita a $50 \%$ do lote a área arrendável para agroindústrias. Por sua vez, essas regras foram formuladas para garantir que os assentados vivam do cultivo da terra, não da renda da terra, o que é uma temática complexa e de alto conteúdo político. Diante desse quadro, baixa fertilidade e limitação ao arrendamento, não é raro nesse assentamento que os agricultores voltados ao mercado queiram vender seus lotes.

Outro fator apontado como limitante é a redução da mão de obra familiar (Tabela 3), agravada pelo envelhecimento da população, problemas de saúde e o êxodo dos jovens, elementos generalizados nas áreas rurais como citado em diversos estudos (ABRAMOVAY, MELLO e SILVESTRO, 2003; DI PIERRO e ANDRADE,

9. Portaria do Itesp n. 075-24/10/02.
2009). Efetivamente, todas as estratégias de reprodução visam solucionar os problemas que, na visão das famílias, limitam o crescimento produtivo e a geração de renda (Tabela 3).

A maior preocupação das famílias voltadas ao mercado local (3), (4) e (5), em última análise, diz respeito à geração de renda, que também é limitada pela restrição de mão de obra, como em estudos de Wanderley (2014). Nesses estabelecimentos, na percepção dos agricultores, a demanda pelos produtos produzidos é maior que sua oferta, explicando sua orientação de investir em um trator agrícola.

Já a comercialização é a fase mais preocupante para os agricultores fornecedores das agroindústrias (1) e (2). Isto também explica a razão de estas explorações serem integradas à agroindústria; afinal, a venda, em princípio, já está garantida por meio de contrato antecipado. No entanto, o agricultor que produz frango e cana-de-açúcar registra a expectativa de diversificação de atividades produtivas, em contraste com o frango e leite, que precisa de mais terra. Essa diferença está associada à limitação de arrendamento para cana-de-açúcar em $50 \%$ do lote, o que faz com que esse agricultor continue dispondo de $50 \%$ do lote para outras atividades, enquanto o que produz leite precisa de mais terra para pasto.

Para reduzir sua dependência das agroindústrias, os agricultores integrados mencionam a busca de formas alternativas de comercialização e processamento da produção (leite) por meio do associativismo. Já nos estabelecimentos voltados 
ao mercado local (3), (4) e (5), o associativismo é visto como algo que: "não dá certo, cada um quer fazer de um jeito", "eles não sabem trabalhar".

De certa forma, é paradoxal constatar que os agricultores integrados declaram que sua estratégia para garantir a comercialização foi justamente a integração, por exigir pequeno investimento de tempo e de preocupação. E mencionam o anseio de processar e comercializar de forma associativa, forma essa que demanda elevado investimento em tempo e preocupação. Por outro lado, os agricultores orientados para o mercado local, ainda que dedicando mais tempo para vender sua produção, não afirmam ter dificuldade na comercialização e não declaram interesse em se associar.

\subsection{Características dos processos de comercialização}

Nos estabelecimentos ligados à agroindústria (1) e (2) os produtos são vendidos por contratos de integração ou compra antecipada. $\mathrm{O}$ contrato é formalizado, mas isso não garante completamente o pagamento pela produção como efetivamente ocorreu na crise de capitais de 2008, em que os estabelecimentos estudados integrados à agroindústria não receberam o pagamento da produção comercializada. Nesta via de venda não há relação com os consumidores, e o prazo de recebimento é de 30, 60 e 90 dias.

Todas as explorações voltadas ao mercado local comercializam em no mínimo dois canais de venda, diversificando seus compradores e segmentos de mercado e, assim, diminuindo os riscos de não pagamento. Os atacadistas normalmente conhecem os agricultores há anos e mantêm uma relação de amizade (BOAS e PIMENTA, 2011). Em certa medida, esses laços limitam o risco de não pagamento, mesmo não havendo qualquer contrato formal. Para os atacadistas, as principais exigências são a qualidade do produto, pontualidade na entrega e preço. Já os varejões, sacolões e quitandas, por serem numerosos em Araraquara, são de mais fácil acesso ao produtor (MACHADO e SILVA, 2004). Em ambos os casos, não há relação com os consumidores e o prazo de recebimento é de normalmente 15 dias.

Na venda direta, é praticamente nulo o risco de não pagamento, já que o produtor recebe à vista. Ademais, proporciona uma relação próxima com o consumidor, possibilitando que o produtor seja o primeiro a processar informações de tendências e alterações no hábito de consumo (CONSTANTY e DAROLT, 2008). Além disso, o contato permite que, em certa medida, o cliente possa também aprender sobre a diversidade e a sazonalidade dos produtos em sua região, de modo que, em longo prazo, sintonize seus hábitos de consumo com as possibilidades de produção do agricultor. Esse contato direto e pessoal e mútuo aprendizado contribuem para a manutenção e o aprimoramento do negócio (CONSTANTY e DAROLT, 2008).

\section{Conclusões}

No processo de tomada de decisões, os fatores que levaram os agricultores a optarem por diferentes vias de comercialização estiveram relacionados fortemente com características familiares. De particular importância foram a disponibilidade de mão de obra e a experiência tecnológica e mercadológica presentes na família, especialmente no chefe da família. A disponibilidade de renda externa à propriedade e a possibilidade de financiamento externo, além do potencial de geração de renda também foram muito relevantes.

Contudo, a importância de cada fator isoladamente variou de família a família. A escolha das vias de comercialização prioritárias resultou de uma ponderação desses fatores, incluindo uma avaliação nem sempre verbalizada do risco implicado na escolha.

As propriedades integradas à agroindústria apresentaram os valores agregados brutos e valores agregados por trabalhador equivalente e exigiram maiores investimentos e risco. $\mathrm{Na}$ crise financeira mundial de 2008, essas propriedades entraram em colapso, junto às indústrias integradoras. 
As propriedades produtoras de hortaliças e orientadas para o mercado local apresentaram valor agregado por trabalhador da mesma ordem de grandeza, independente da forma de comercialização, contrariando a ideia de que a venda direta é sempre mais vantajosa. Além disso, a escolha da forma de comercialização esteve associada ao tamanho da família, apenas as maiores podendo destacar membros para dedicar tempo à venda. Nenhuma das propriedades produtoras de hortaliças sofreu impacto com a crise financeira.

Por um lado, o estudo conjunto desses casos revelou a complexidade da tomada de decisões quanto à estruturação da produção e à escolha da sua via de escoamento. Por outro, revelou a inadequação de propostas de inserção no mercado que queiram abranger todos os agricultores de um assentamento, sem considerar as motivações e situações específicas de cada família.

\section{Referências}

ABRAMOVAY, R. Agricultura familiar e desenvolvimento territorial. Reforma Agrária - Revista da Associação Brasileira de Reforma Agrária, v. 28, n. 1,23 e 29, n. 1, p. 1-21, jan./dez. 1998.

., MELLO, M. A. e SILVESTRO, M. L. Sucessão hereditária e reprodução social da agricultura familiar. Agricultura, São Paulo, v. 50, n. 1, p. 11-24, 2003. Apresentado no Congresso da Sober XLIV. 2006 Fortaleza. Disponível em: < http://www.sober.org.br/ palestra/5/191.pdf>. Acesso em: 28 dez. 2014.

ALENTEJANO, P. R. Reforma Agrária e pluriatividade no Rio de Janeiro: repensando a dicotomia rural-urbana nos assentamentos rurais. Rio de Janeiro: Curso de Pós-Graduação em Desenvolvimento, Agricultura e Sociedade, Universidade Federal Rural do Rio de Janeiro, 1998. (Dissertação de Mestrado em Ciências em Desenvolvimento, Agricultura e Sociedade).

ANTUNIASI, M. H. R. Família e trabalho em assentamentos rurais. Cadernos CERU, São Paulo: série 2, n. 7, p. 97-107, 1997.

BOAS, L. H. B. V. e PIMENTA, M. L. Relacionamento entre produtores e atacadistas de hortaliças sob a ótica de economias políticas: Um estudo de caso empírico sobre Díades de Canal. Revista Brasileira de Gestão e
Engenharia, v. 4 p. 14-33, 2011 Disponível em: < http:// periodicos.cesg.edu.br/index.php/gestaoeengenharia/ article/view/28 > . Acesso em: 28 dez. 2014.

BORGES, J. R. P., FABBRO A. L. D. e RODRIGUEZ A. L. Percepção de riscos socioambientais no uso e agrotóxicos o caso dos assentados da reforma agrária paulista. Encontro Nacional de Estudos Populacionais, Caxambu: ABEP 2004, Caxambu MG. Disponível em: <http:// www.abep.nepo.unicamp.br/encontro2006/docspdf/ ABEP2006_126.pdf>. Acesso em: 28 dez. 2014.

CAMPOI, A. M. Sistemas de produção e estratégias de vida: um estudo no projeto de assentamento Monte Alegre Araraquara, SP. 2005, 201 p. Dissertação (Mestrado em Desenvolvimento Regional e Meio Ambiente), Centro Universitário de Araraquara, Araraquara, 2005.

CHALITA, M. A. N. e PANZUTTI, N. P. M. Significados $e$ identidades nas transformações da agricultura familiar. Disponível em: <ftp://ftp.sp.gov.br/ftpiea/publicacoes/ tec2-1106.pdf>. Acesso em: 20 dez. 2014.

CHAYANOV. A. V La organización de La unidad econômica campesina. Buenos Aires, Nueva Vison 1974132 p.

CONSTANTY, H. e DAROLT, M. R. Estratégias de fortalecimento da relação entre produtores e consumidores orgânicos. In: Fórum Internacional do Complexo Agroindustrial Orgânico e Biotecnologias. Curitiba; 2008. Complexo Agroindustrial Orgânico. Curitiba PR: Orgânica, p. 44-48, 2008. Disponível em: $<$ http://www.iapar.br/arquivos/File/zip_pdf/darolt_ constanty08.pdf $>$. Acesso em: 28 dez. 2014.

CONTERATO, M. A. A., SILVA, C. C. e KOPPE, L. R. Pluriatividade e qualidade de vida dos agricultores familiares no Rio Grande do Sul. Apresentado no Congresso da Sober XLV 2007 Londrina. Disponível em: < http:// www.sober.org.br/palestra/6/334.pdf $>$. Acesso em: 28 dez. 2014.

DI PIERRO, M. C. e ANDRADE, M. R. Escolarização em assentamentos no estado de São Paulo: uma análise da Pesquisa Nacional de Educação na Reforma Agrária 2004. Rev. Bras. Educ., v. 14, no 41, p. 246-257, 2009. Disponível em: <http://www.scielo.br/pdf/rbedu/ v14n41/v14n41a04.pdf>. Acesso em: 28 dez. 2014.

DUFUMIER, M. Projetos de desenvolvimento agrícola: manual para especialistas. 2. ed. Salvador: Edufba, 2010. 326 p.

DULLEY, R. D., SILVA V. e ANDRADE, J. P. Estrutura produtiva e adequação ao sistema de produção orgânico. Informações Econômicas, v. 33, p. 14-23, 2003. Disponível em: <http://www.iea.sp.gov.br/OUT/publicacoes/pdf/ tec2-1103.pdf>. Acesso em: 28 dez. 2014. 
FAZENDA MALUNGA FAZENDA MALUNGA Reportagem exibida no dia 18 de out. 2009 Globo Rural. Disponível em: <https://www.youtube.com/watch?v= 39hJnzbWuDM > e < https://www.youtube.com/watch?v $=\mathrm{cSYVsdYPN8Y>}$. Acesso em: $28 \mathrm{dez} .2014$.

FEIDEN, A. Metodologia para análise econômica em sistemas agroecológicos - 1a Aproximação: Análise de culturas individuais. Embrapa Agrobiologia. Documento 141, Rio de Janeiro: Seropédica: Embrapa Agrobiologia, dez $200130 \mathrm{p}$.

FERRANTE, L. S. B. Dinâmicas familiar, produtiva $e$ cultural nos assentamentos rurais de São Paulo. Araraquara: UNIARA, Campinas: FEAGRI/UNICAMP, São Paulo: INCRA, p. 65-78, 2003.

FERRANTE, V. L. B. e DUVAL, H. C. Mulheres assentadas na região central do estado de São Paulo: apresentado dados de pesquisas. João Pessoa, 2012. Disponível em: $\quad<$ http://www.ufpb.br/evento/lti/ocs/index. php/17redor/17redor/paper/viewFile/254/112>. Acesso em: 28 dez. 2014.

FIGUEIREDO, A. M. et al. Integração na criação de frangos de corte na microrregião de Viçosa - MG: viabilidade econômica e análise de risco. Rev. Econ. Sociol. Rural [online], 2006, v. 44, n. 4, p. 713-730. Disponível em: <http://dx.doi.org/10.1590/S010320032006000400005 > . Acesso em: 28 dez. 2014.

GONÇALVES, A. A. e CEZARINI, R. Agregando valor ao pescado de água doce: defumação de filés de Jundiá (Rhamdia quelen). Rev. Bras. Enga. Pesca, v. 3, n. 2, jul. 2008. Disponível em: <http://ppg.revistas.uema.br/ index.php/REPESCA/article/viewFile/73/72>. Acesso em: 28 dez. 2014.

GRAZIANO SILVA e DEL GROSSI. O novo rural: uma abordagem ilustrativa. Londrina: IAPAR, v. 1, 53 p., v. 2, 1-49 p. 2002.

IBGE. Censo Agropecuário 2006. Rio de Janeiro, RJ: p. 1-146, 2007.

INNOCENTINI, R. C. P. Análise dos custos de produção de frango de corte nos sistemas integrados e independentes. Veterinárias Notícias, v. 15, n. 2, 2009. Disponível em: <http://www.seer.ufu.br/index.php/ vetnot/article/view/18922 > . Acesso em: 23 dez. 2014.

KAGEYAMA, A. O subemprego agrícola nos anos 90. Nova Economia, Belo Horizonte, v. 7, n. 1, p. 83-98, maio 1997.

KHATOUNIAN C. A. A reconstrução ecológica da agricultura. Botucatu: Agroecológica, 2001, 348 p.

LAMARCHE, H. (Coord.). Agricultura Familiar: comparação internacional: do mito à realidade. Vol II. Trad.
Frédéric Bazin. Campinas: UNICAMP, 1998. 348 p. (Coleção Repertórios)

LOPES, L. A. B. Efeitos da integração vertical na sustentabilidade dos empreendimentos rurais: o caso da goiaba no estado de São Paulo. Dissertação (Mestrado). São Carlos Curso de Pós-graduação em Ciências Ambientais, UFSCar, 2006. 156 p.

LUZ, J. M. Q., SHINZATO, A. V. e SILVA, M. A. D. C. Comparação dos sistemas de produção de tomate convencional e orgânico em cultivo protegido. Biocence Journal, v. 23, n. 2, p. 7-15, 2007. Disponível em: <ww. seer.ufu.br/index.php/biosciencejournal/article/ download/.../4531 > . Acesso em: 28 dez. 2014.

MACHADO, M. D. e SILVA, A. L. Distribuição dos produtos provenientes da agricultura familiar: um estudo de Caso. Revista de Administração da UFLA, Lavras, MG, v. 6, n. 1, jan./jun. 2004.

MARTINS, J. S. O sujeito Oculto. Porto Alegre: Ed. UFRGS, 2003, $238 \mathrm{p}$.

MEDEIROS, L. et al. Impacto dos assentamentos: um estudo sobre o meio rural brasileiro. Brasília/São Paulo, NEAD/Ed. Unesp, 2004, 392 p.

ROCHA, C. H. et al. Perfil Socioeconômico dos feirantes e consumidores da Feira do Produtor de Passo Fundo, RS. Rev. Ciência Rural, Santa Maria, 2010. Disponível em: $<$ http://www.scielo.br/pdf/cr/2010nahead/a801cr1599. pdf>. Acesso em: 23 dez. 2014.

SACCO DOS ANJOS, F. Agricultura Familiar, Pluriatividade e Desenvolvimento Rural no Sul do Brasil. Pelotas: EGUFPEL, 2003, $374 \mathrm{p}$.

SCHNEIDER, S. Teoria social, agricultura familiar e pluriatividade. RBCS, v. 18, n. 51, fev. 2003. Disponível em: $\quad<$ http://www.scielo.br/scielo.php?script=sci_artt ext\&pid $=$ S0102-69092003000100008 $>$. Acesso em: 28 dez. 2014.

SOUZA, R. A. M.; SILVA, R. O. P.; PAGOTTO, A. M. Comercialização hortícola: análise de alguns setores do mercado varejista de São Paulo. Informações Econômicas, v. 28, n. 10, out. 1998. Disponível em: < http://www.iea download/tec1-1098.pdf>. Acesso em: 28 dez. 2014.

WANDERLEY, M. N. B. O mundo rural como um espaço de vida: reflexões sobre a propriedade da terra, agricultura familiar e ruralidade. Ed. UFRGS, 2009, 300 p.

. Agricultura familiar e campesinato: rupturas e continuidade. Estudos Sociedade e Agricultura, v. 22, n. 22, 2014. Disponível em: < http://r1.ufrrj.br/esa/V2/ojs/ index.php/esa/article/view/238/234>. Acesso em: 28 dez. 2014. 
